\title{
Recent Advances in Agent-Based Tsunami Evacuation Simulations: Case Studies in Indonesia, Thailand, Japan and Peru
}

\author{
Erick Mas, ${ }^{1}$ Shunichi Koshimura, ${ }^{1}$ Fuminiko Imamura, ${ }^{1}$ Anawat Suppasri, ${ }^{1}$ Abdul Muhari, ${ }^{2}$ and \\ BRUNO ADRIANO ${ }^{3}$
}

\begin{abstract}
As confirmed by the extreme tsunami events over the last decade (the 2004 Indian Ocean, 2010 Chile and 2011 Japan tsunami events), mitigation measures and effective evacuation planning are needed to reduce disaster risks. Modeling tsunami evacuations is an alternative means to analyze evacuation plans and possible scenarios of evacuees' behaviors. In this paper, practical applications of an agent-based tsunami evacuation model are presented to demonstrate the contributions that agent-based modeling has added to tsunami evacuation simulations and tsunami mitigation efforts. A brief review of previous agent-based evacuation models in the literature is given to highlight recent progress in agent-based methods. Finally, challenges are noted for bridging gaps between geoscience and social science within the agent-based approach for modeling tsunami evacuations.
\end{abstract}

\section{Introduction}

The 2004 Indian Ocean tsunami (IOT) was one of the deadliest disasters in recent history due to the extreme tsunami heights combined with insufficient warning, awareness, and early evacuation responses. Since its occurrence, the event has been used as a learning tool. This event likely marked the first time that people watched videos or pictures of a devastating tsunami event. Among those pictures, SynOLAKIS and BERNARD (2006) noted the surprising images of tourists in Phuket, Thailand, watching the approaching tsunami without taking any protective action. Unfortunately, the Indian Ocean did not have a tsunami warning system at that time, so no warnings could reach the people in the affected areas.

\footnotetext{
1 International Research Institute of Disaster Science (IRIDeS), Tohoku University, Sendai, Miyagi, Japan. E-mail: mas@irides.tohoku.ac.jp

2 Ministry of Marine Affairs and Fisheries, Jakarta, Indonesia.

3 Graduate School of Engineering, Tohoku University, Sendai, Miyagi, Japan.
}

However, would these people have reacted to warning information? This is an important question because tsunami risk involves not only a hazard assessment but also a social component of human behavior because evacuation is the best option for saving lives during a tsunami (SHuTo 2009).

Similarly, the 2011 Great East Japan tsunami (GEJT) was one of the most destructive tsunami events in modern history, although it provided lessons for preparing for future events. The large inundation and tsunami heights (SUPPASRI et al. 2012a) destroyed several towns and villages along the Japanese coast. However, the survival rate of the people living in the inundated areas was $96 \%$ (SuPPASRI et al. 2012b; FRASER et al. 2012).

Fatality rates were lower for the 2011 GEJT event, compared with the 2004 IOT in Indonesia (SUPPASRI et al. 2014; MAS et al. 2013b), despite the numerous towns struck by larger tsunami heights. What caused these different outcomes? A plausible answer could be that not only structural countermeasures but also rapid dissemination of warning information, disaster education, tsunami awareness, and, in particular, evacuation responses contributed to strongly reducing the casualties in the 2011 GEJT. Both tsunami events confirmed the importance of early evacuation and tsunami awareness and the need to develop much more resilient communities with effective evacuation plans.

Therefore, following these lessons provided by the most destructive tsunami events in recent times, we aim to highlight the importance of tsunami evacuation planning and to present a tool to support such an activity. Four international case studies were chosen to describe practical applications of casualty and bottleneck estimation and analyses of vehicles in evacuation, human behavior and shelter demand, all 
of which contribute to tsunami mitigation and evacuation planning. The use of tsunami evacuation simulations attempts to support reconstruction activities in Japan and efforts to develop resilient communities in at-risk areas in Indonesia, Thailand and Peru.

\section{Tsunami Evacuation Modeling}

The second part of this section presents a comprehensive summary of agent-based models for tsunami evacuation, although the section does not provide an extensive review of all the various models available. We wish to clarify our motivation for focusing on the agent-based approach instead of other methods. First, what are agent-based models?

Agent-based model (ABM): it is a bottom-up approach in which each agent or individual part of a system is modeled as an autonomous decisionmaking entity. Each agent follows particular rules according for their role in the system; thus, they are able to execute various behaviors. The interaction of these parts and their behaviors develops into a macro description of the system based on an emergent phenomenon.

ABMs are flexible and capture the emergent phenomena from a natural description of a system such as a community and its individual members. Therefore, an $\mathrm{ABM}$ is ideal for simulating disaster emergency evacuations (MunADI et al. 2012) because it provides valuable insight into the mechanisms and behavior that result in jamming or casualties.

There are several other approaches used in tsunami evacuation models that can be found in the literature, e.g., genetic algorithms (PARK et al. 2012), Geographic Information System (GIS) (Sugimoto et al. 2003; Clerveaux et al. 2008; Wood and Schmidtlein 2012; Dewi 2012; Freire et al. 2012; GonZaLEZRIANCHO et al. 2013) distinct or discrete element methods (DEMs) (ABUSTAN et al. 2012), and system dynamic approaches (Simonovic and Ahmad 2005; KIETPAwPan 2008). However, GIS approaches are traditionally top-down methods that use aggregate descriptions of a system. In evacuation, the complexity and diversity of behaviors that are interrelated produce dynamic changes that GIS models are not well suited to tracking (CASTLE and CROOKS 2006) unless they incorporate micro-scale components provided by ABMs (Johnston 2013). Similarly, system dynamic approaches might be able to track system changes throughout a simulation; however, they lack spatial complexity and require many assumptions about the system if applied to simulating evacuation procedures. In addition, DEMs apply physical laws, such as fluid dynamics, to the evacuees. Such a representation may provide a good description of large crowd behavior during an evacuation (HELBING et al. 2005); however, not all phenomena follow Newtonian motion because psychological forces or sudden changes in motion are likely to occur.

In summary, we choose to focus on $\mathrm{ABM}$ due to its benefits over other model techniques for capturing emergent phenomena and providing a natural description of a system. ABM is also flexible for scaling, tuning agent complexity and behavior, and has the capability to use modern data with a higher level of detail.

\subsection{Agent-Based Tsunami Evacuation Modeling}

One of the first tsunami evacuation models published (Usuzawa et al. 1997) can be found in the Japanese literature. The model simulates the evacuation of Aonae on Okushiri Island, which was affected by the 1993 Hokkaido earthquake. In this initial model, a network modeling approach, which is commonly used to simulate evacuations from hurricanes, floods, nuclear disasters and fires in buildings (WAtTs 1987), was used as the modeling method. Following the research of Usuzawa et al. (1997), IMAMURA et al. (2001) described another network model for the same area, but this study included a different start time for each agent in the evacuation and control parameters to distinguish pedestrians from vehicles in the calculation. The computational method uses sequential programming, so all of the evacuees move at the same time and decisions are scheduled only at intersections or the nodes of the network. In addition, in this model, agents jump from node to node in the step that corresponds to the relationship between their speed and road length, limiting the analysis of crowding or the dynamics of pedestrians during the simulation. Later, FuJiokA 
et al. (2002) proposed a much more complex representation of evacuees by formally introducing multi-agent systems to tsunami evacuation simulations. The model represented evacuees and guides as agents with different objectives and communication capabilities. This study was one of the most advanced representations of human behavior in the tsunami evacuation field at the time. Although the model uses a combination of network- and grid-based roads, the agent collision avoidance dynamics were limited because the speed was fixed for all of the agents throughout the simulation. In addition, the model returned to the total compliance approach for the evacuation start time, which is less realistic than the different timing approach used by Imamura et al. (2001). Saito and Kagami (2004) presented an agentbased model similar to the model of Imamura et al. (2001); they modeled the movement of agents using results from a questionnaire about residents' preferences for the start time of evacuations. However, preference surveys alone are not sufficient to describe evacuees' behavior because post-event surveys have demonstrated that actual behavior may differ from the expected behavior. The importance of human behavior in tsunami evacuation simulations gained the attention of researchers in the field (SUZUKI and ImAMURA 2005). Nonetheless, from the point of view of pedestrian dynamics, tsunami evacuation models lacked a clear approach for path finding because the main rule given to agents was to proceed to the next highest node in the network instead of searching for the shortest path or a specific goal. The model developed by KatADA et al. (2004) incorporated a routing method to find the shortest path in the network. Moreover, while previous studies tried to answer specific research questions, Katada's model moved tsunami evacuation simulations from scientific research to practical applications for tsunami mitigation, particularly for disaster education and outreach. The Tsunami Scenario Simulator (KATADA et al. 2000) was developed as a GIS model to investigate information dissemination during disasters; it was later modified (KATADA and KuwASAwA 2006) into the Tsunami Dynamic Hazard Map for disaster education purposes. This tool allowed citizens to dynamically observe the consequences of many of their potential evacuation decisions. Since this modification, the literature on tsunami evacuation models using agent-based techniques has increased considerably (Meguro and Oda 2005; Nozawa et al. 2006; Watanabe and Kondo 2009; Goto et al. 2012).

Increases in computational power have enabled the analysis of large amounts of data and have made it possible to shift the modeling approach from network-based (IMAMURA et al. 2001; LäMmel et al. 2010) to grid-based (MAs et al. 2012), potential fields (Meguro and Oda 2005), or hybrid modeling approaches to improve realism in pedestrian dynamics and collision avoidance behaviors (FusIOKA et al. 2002; Kato et al. 2009; NGuyen et al. 2012a). Gradually, the research methodology has moved toward using much more data with finer levels of detail through agent-based modeling and high-performance computing (WiJERATHNe et al. 2013). In addition, the importance of human behavior in evacuations is increasingly being considered in models (Suzuki and Imamura 2005; Mas et al. 2012; FujIOKa et al. 2002). Following the 2004 IOT and 2011 GEJT, tsunami evacuation modelers have focused on providing practical applications of simulations to solve the particular problems that were observed in these events, such as evacuation timing, bottlenecks and traffic congestion from vehicle evacuations, shelter locations, evacuee behavior, and risk communication, among other factors. In addition, reconstruction in tsunami-affected areas requires new evacuation plans that follow new urban layouts. Effective evacuation plans to be executed under new urban spatial conditions can initially be analyzed and evaluated using evacuation models. In the next section, we describe applications of an ABM tsunami evacuation model that integrate tsunami inundation features and human behavior during evacuations.

\section{Case Studies of the Practical Applications of Tsunami Evacuation Simulations}

The simulation of tsunami evacuations is becoming important to investigate potential responses to warnings, estimate potential casualties, evaluate evacuation plans and explore options for tsunami mitigation. These experiments are guiding the 
development of more effective educational and mitigation programs in many countries (BERNARD et al. 2006). Here, we demonstrate several examples of case studies of ABM tsunami evacuation modeling applied to verify, analyze and evaluate actual or predicted tsunami scenarios for evacuations. A large body of literature on agent-based tsunami evacuation models is available for several areas (WIJERATHNE et al. 2013; Gото et al. 2012; NGUYen et al. 2012b; Abustan et al. 2012; LÄMmel et al. 2010; Meguro and Oda 2005; KatAdA et al. 2004); however, for brevity and consistency, we will introduce case studies and mitigation-related results from one agentbased model.

\subsection{Casualty and Bottleneck Estimation: Cases of Arahama, Japan and Padang, Indonesia}

The agent-based model described in this paper incorporates tsunami inundation modeling outputs and pedestrian and vehicle agent simulation (MAS et al. 2012). The model was verified using the 2011 GEJT data from the evacuation in Arahama, Sendai, Japan (Fig. 1).

One thousand iterations of a stochastic simulation were conducted; each simulation provided the number of evacuees at a shelter, the number of evacuees who passed one of the exits ("safe") and the number of evacuees trapped by the tsunami (the probability of becoming a casualty exceeded $50 \%$ ) (Fig. 2). This information at such a high level of detail is one of the greatest advantages of agent-based modeling. In addition to emergent behavior, the behavioral details of each agent and local issues (e.g., traffic and crowd congestion due to the number of agents or the presence of slow-speed agents in front of fast agents) can be identified. The exact values from a real situation are difficult to obtain with stochastic simulations; however, the average number of estimated survivors at the tsunami evacuation building (TEB) showed that the model realistically represents some evacuation decisions and outcomes in the area.

Previous models that did not employ an agentbased approach have also been able to provide casualty estimations and sometimes identify bottleneck areas; however, because those methods (i.e., GIS and DEM) are static or aggregated, information on possible timing and details of interactions, e.g., vehicle-pedestrian interactions, cannot be determined.

The tsunami evacuation simulation demonstrated the capability of the model to identify bottlenecks and to verify the evacuation process with several behavioral conditions within a dynamic framework. The stochastic simulation and the individual level of representation in the model provide the modeler with a reasonable amount of data to analyze and identify
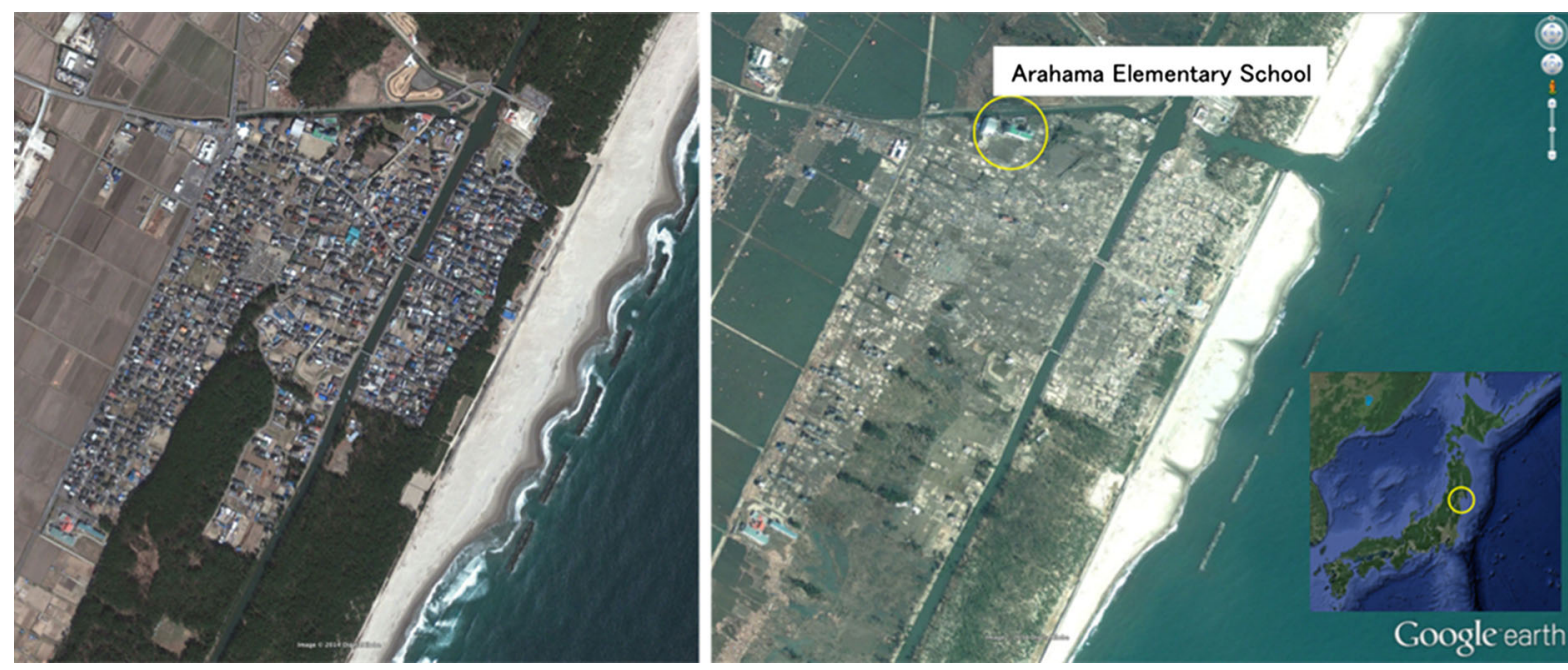

Figure 1

Google Earth images of the Arahama area before (April 4, 2010) and after (March 14, 2011) the tsunami. The yellow circle shows the location of Arahama Elementary School 

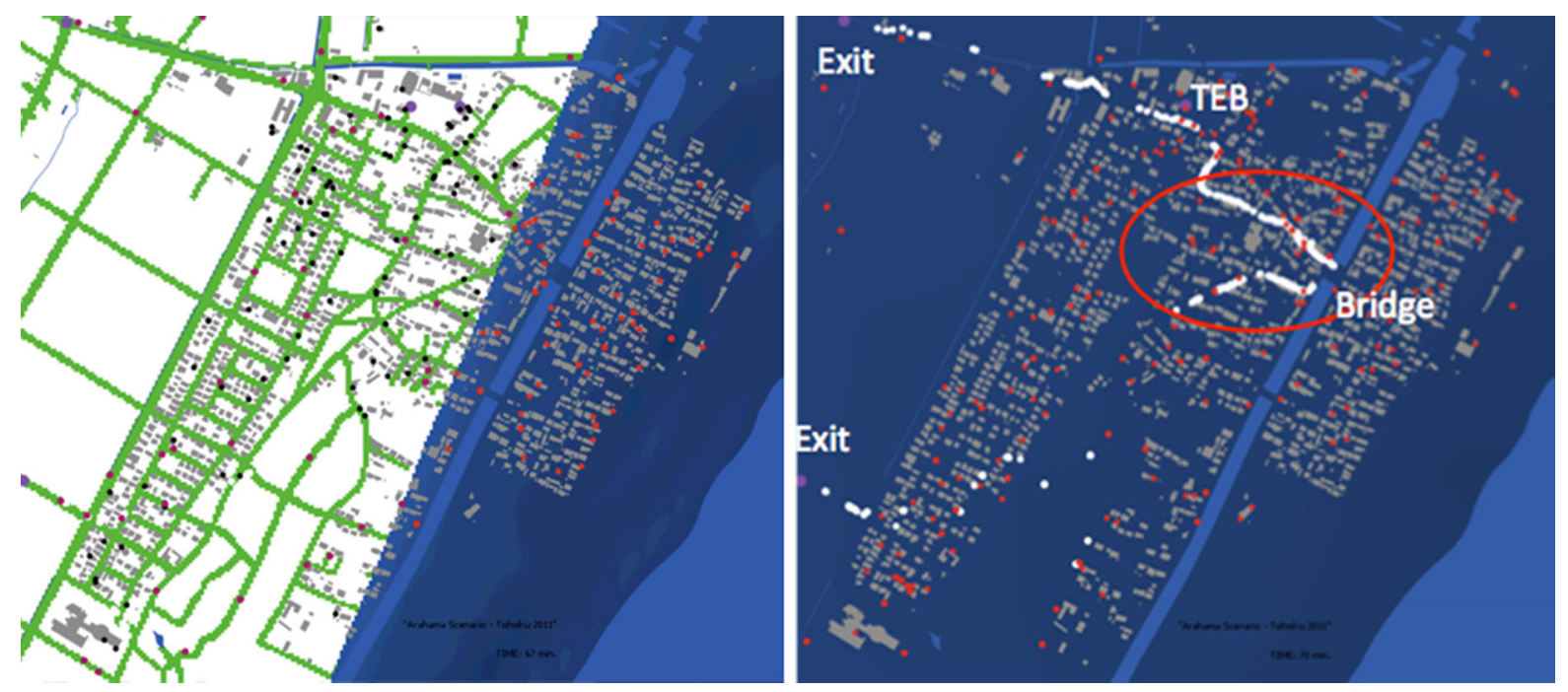

Figure 2

Left A snapshot of the model applied to the Arahama evacuation when the tsunami inundates the study area. The black dots are active pedestrian evacuees; the purple dots are the evacuees in vehicles, and the red dots are fatalities caused by the tsunami. Right The last snapshot of the simulation shows bottleneck areas during the evacuation as white dots. These bottlenecks mainly occurred on the bridge and in front of Arahama Elementary School, which is the evacuation building

issues at both large and small scales, where agent behavior might not contribute to the safe evacuation of other individuals. For example, agents that are slow to begin evacuating increase their own risk of fatality and reduce the flow of evacuation in the network by creating bottlenecks, especially when their speed is also comparatively low.

In addition to verification of past events, ABM models can be used to assess hypothetical events such as a large tsunami affecting Padang City, Indonesia. IMAMURA et al. (2012) described the tsunami hazard in this area based on a mega-thrust earthquake scenario for tsunami simulation using high-resolution bathymetry and topography data. The resulting inundated area was approximately $25 \mathrm{~km}^{2}$, threatening at least 235,000 people with tsunami depths from $3 \mathrm{~m}$ to approximately $8 \mathrm{~m}$ (MUHARI et al. 2011). Padang city lacks vertical evacuation facilities within the predicted inundation area and based on reports from tsunami evacuations during the 2007, 2009 and 2010 events (Hoppe and MarhadiKo 2009), residents mainly use vehicles and motorcycles for evacuation, despite the experiences of traffic congestion. Consequently, estimating the time needed by evacuees to leave the tsunami inundation area and determining possible congested routes during evacuation are necessary.
A total of 104,352 agents were modeled in a $15 \mathrm{~km}^{2}$ area in southern Padang using agent-based modeling (MAs et al. 2012). Based on the size of the modeled population and the evacuation behavior that considers individual departure times, the model calculated casualty estimates, the time needed for evacuation, and bottleneck points (Fig. 3). In the simulation, the tsunami resulted in the fatalities of approximately $37.7 \%$ of the population. The authors identified several congested streets in the northern study area due to the popular use of the exit points. In addition, the shopping center and traditional market center areas were highly congested due to the high local population density. In the south of the evacuation simulation domain, the agents evacuated to high ground by crossing the river; however, based on the tsunami simulation results, those areas are expected to be inundated due to overtopped river embankments.

The application of the tsunami evacuation simulation in these case studies clarifies the importance of evacuation start times, which cannot be explored with aggregated modeling approaches, the need for high evacuation areas, and the sensitivity of streets to congestion in highly populated urban cities, such as Padang. The same area was evaluated as a case study by LÄMMEL et al. (2010) a multi-agent traffic 


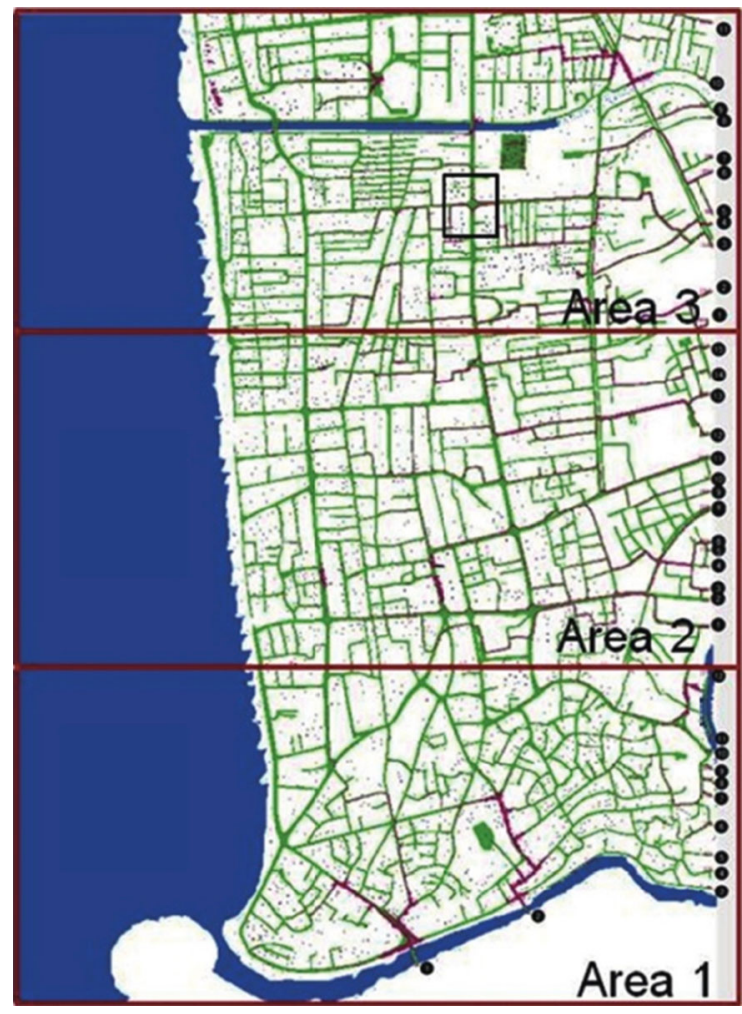

Figure 3

Simulation of evacuation areas, with the bottleneck results shown in purple. Details of other results are reported by Imamura et al. (2012)

simulator (MATSim) to represent pedestrian agents instead of vehicles. While the approach used in the MATSim simulation differs from the model presented here, similar results were obtained. The models exhibited similar results because the agent behavior in path-finding or route-planning for evacuation was primarily set to use the shortest path. LäMmEL et al. (2010) noted that a risk-cost function should be added to the route-planning algorithm in MATSim; similarly, in our model, a risk-cost value for the cells near the tsunami flooding areas might be included. However, before such modifications, it is necessary to investigate the residents' preferences in an evacuation to adequately represent the evacuees. It is possible that some people prefer short routes with earlier starting times, while others prefer longer routes with lower risk. It is recommended to pursue an early starting time and low-risk routes during tsunami evacuations. Padang city is a highly populated area with narrow streets that contribute to immediate crowding. These characteristics make this scenario suitable for modeling using the agent-based approach. However, areas with wide roads, where crowding might not be expected, may use other approaches, such as the least-cost distance (LCD) in GIS (Wood and SchmidtLein 2012), to obtain evacuation timings. In summary, correctly applying tsunami evacuation models depends on the purpose of the simulation and the assumed agent behavior.

\subsection{Vehicles in Evacuation: Case of Pakarang Cape, Thailand}

Another concern for evacuation planning is the use of vehicles during evacuation. This option must be evaluated according to the characteristics of the environment and the population involved in the evacuation. MAs et al. (2013b) conducted an evacuation simulation for the Pakarang Cape in Thailand, located in the Khao Lak beach resort area of Phang Nga Province on the Andaman Sea, an area devastated by the 2004 IOT (Fig. 4).

A total of 2649 residents were modeled based on a nighttime population scenario. The objective in this case study was to explore the influence of vehicles on the evacuation, combined with different reaction times from the residents. A set of percentages of evacuees in vehicles (passengers and drivers) was assumed for developing several scenarios for the simulation. The evacuation rate as a function of time followed the results of a questionnaire survey (SuPPASRI 2010). In addition to this distribution, three other scenarios were considered: a late evacuation and two intermediate scenarios between the former two distributions. The results of the 20 simulated cases are shown in Fig. 5. Due to differences in reaction time and the long evacuation distance, the use or non-use of vehicles was found to contribute to fatality rates, which ranged from 6 to $34 \%$ of the total population at risk.

The application of the tsunami evacuation simulation in this case study showed the capability of ABM to evaluate the feasibility of evacuations and on-road vehicle-pedestrian interactions. In this case, 20 scenarios with different evacuation starting times and percentages of vehicles used in the evacuation were compared. The results suggest that because of 

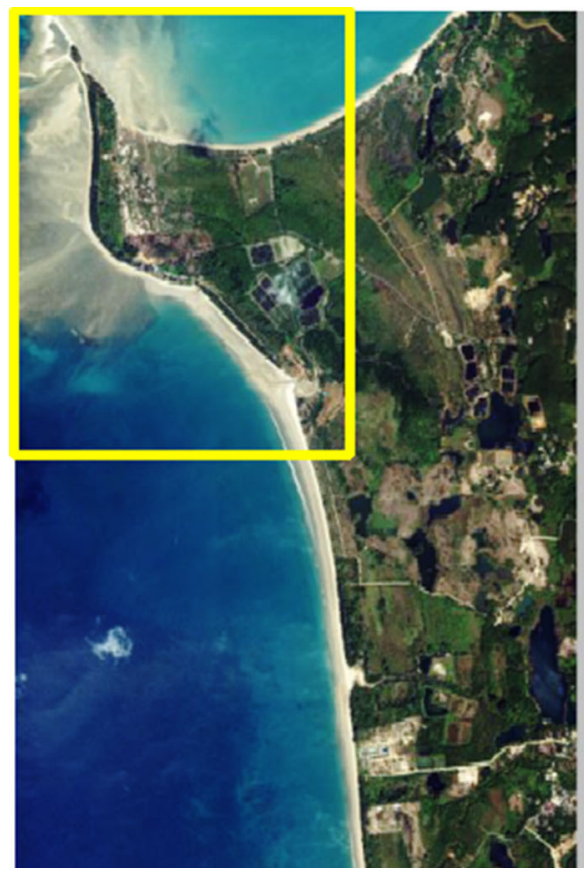

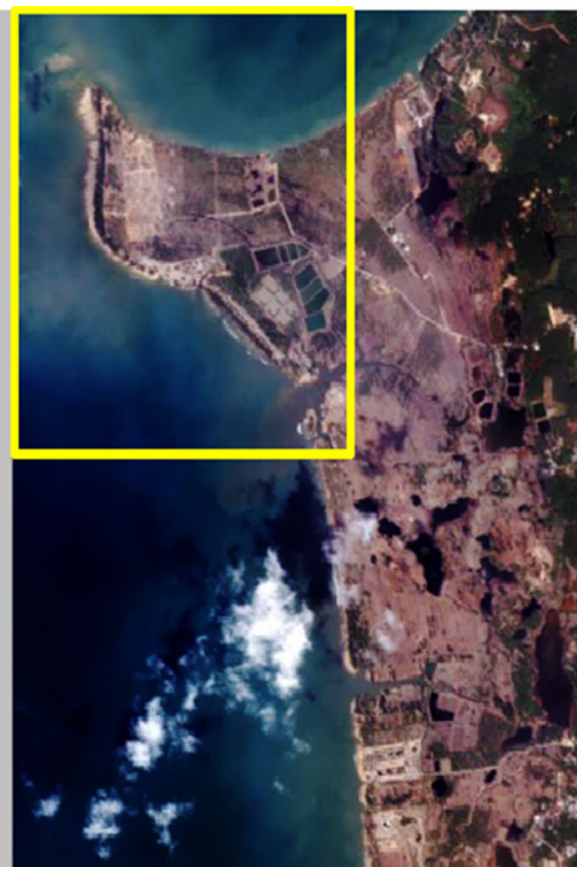

Figure 4

Phang Nga devastation from the 2004 Indian Ocean tsunami. Left January 13, 2003. Right December 29, 2004. Source: Space Imaging/ CRISP-Singapore. The yellow inset shows the simulated area

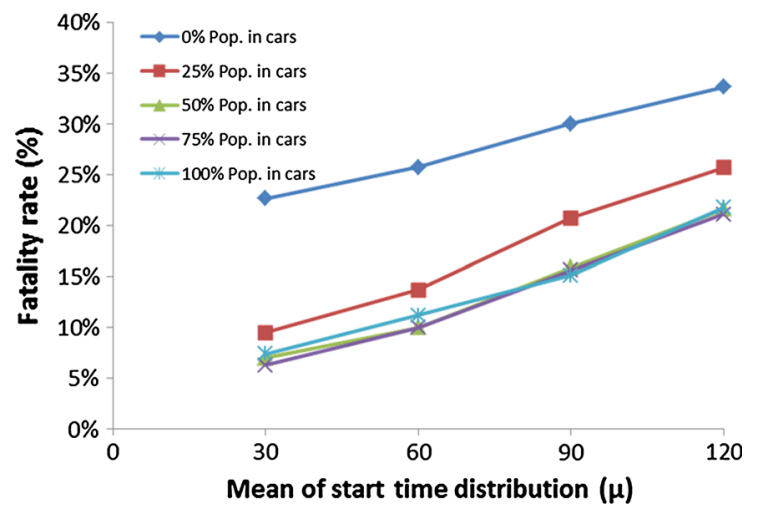

Figure 5

Fatality ratios for different evacuation timing scenarios and the percentages of the population using vehicles. Note the advantage of a fast evacuation decision and the advantage of using cars in this specific case

the distance to the shelters, vehicle evacuation might be necessary. It is possible that the use of vehicles in this area might not result in significant traffic congestion due to the small population and sufficient road capacity. Note that with a larger population than evaluated here, traffic congestion is possible, as shown in the Arahama case study. This suggests that conclusions from tsunami evacuation simulations in one area should not be arbitrarily applied to another area, particularly with regard to restrictions on vehicles for evacuation.

\subsection{Evacuation Behavior: Case of Natori, Japan}

This is the second application of a tsunami evacuation model to the 2011 GEJT (Fig. 6). TAKAGI et al. (2014) simulated the evacuation behavior reported in Yuriage, Natori, to replicate the evacuation process and investigate the reasons for the large number of fatalities in the area. Yuriage is a small town near the Natori River located on the plains of the Miyagi Prefecture. Before the earthquake on March 11, 2011, approximately 5612 residents were living in the area. After the earthquake, 752 people were killed by the resulting tsunami, and 41 are still missing; this event resulted in one of the highest fatality rates in the plains area of Miyagi.

Reports indicate that the residents in the area evacuated to nearby shelters; however, before the tsunami arrived, the tsunami warning was elevated to reflect a larger estimated tsunami height (JMA 2013). 

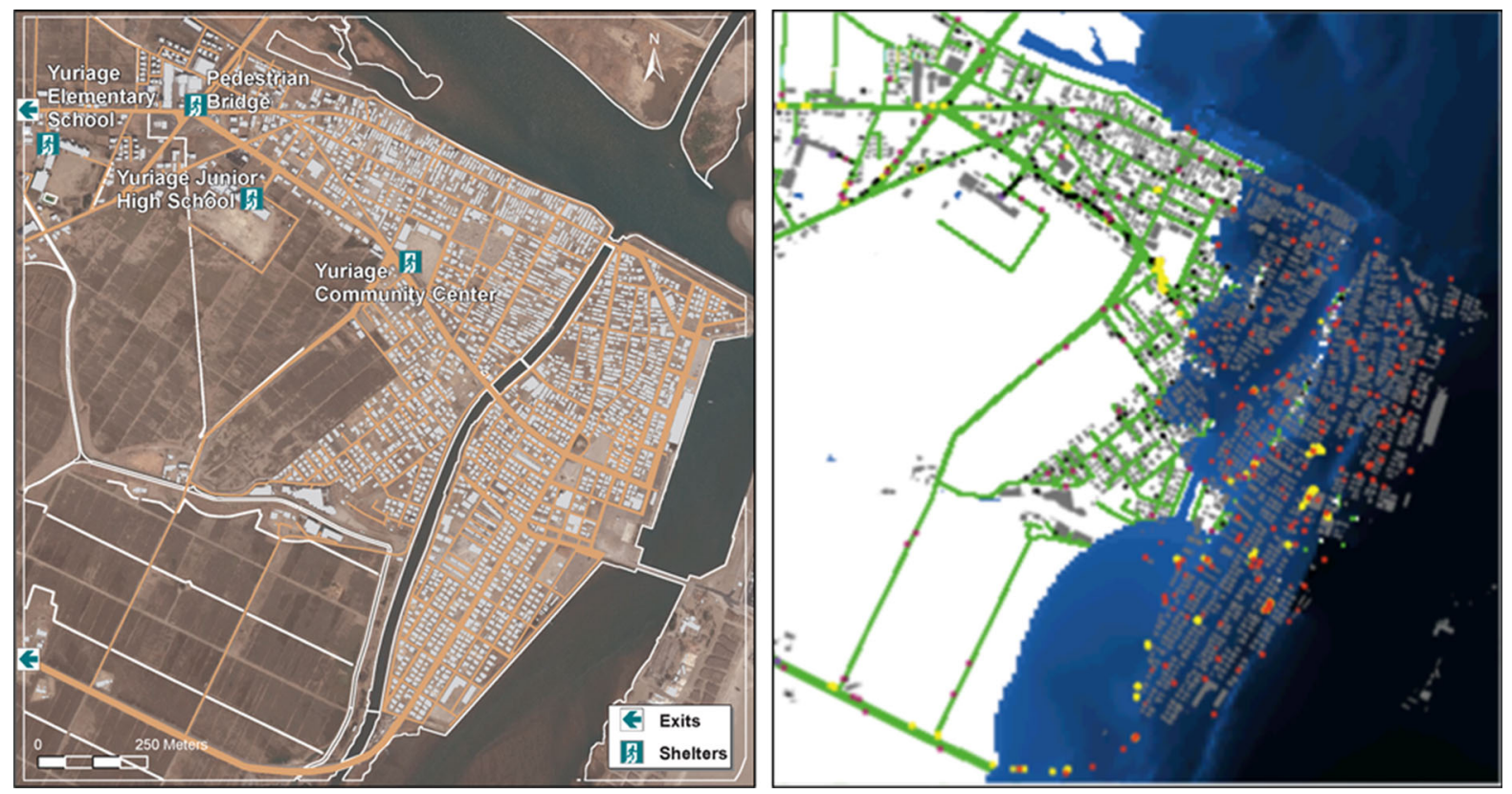

Figure 6

Left The study area of Yuriage in Natori, Miyagi Prefecture, Japan. From right to left (landwards): the green signs indicate the locations of the Yuriage Community Center, Yuriage Junior High School, pedestrian bridge (not official) and Yuriage Elementary School, respectively. The green arrows are the exit routes for vehicle evacuations. Right A snapshot of the model applied in Yuriage, Natori. The study area is inundated by the tsunami based on the numerical simulation results. The black dots are the active pedestrian evacuees; the purple dots are evacuees in vehicles; the red dots are fatalities due to the tsunami; and the yellow dots show the bottleneck points in the simulation

Therefore, over the next few minutes, some of the evacuees decided to conduct a secondary evacuation to a more inland shelter. Evacuees in the community center, which is a 2-story building, moved to Yuriage Junior High School, which is a 3-story building located approximately $500 \mathrm{~m}$ inland (Fig. 6). During this second evacuation, the arrival of the tsunami (MuHARI et al. 2012) resulted in pedestrian fatalities. In this case study, the model was applied to two scenarios: (1) Case A, a scenario as close as possible to the real evacuation based on the data reported by local authorities and survivors and (2) Case B, a what-if scenario in which the second evacuation was not performed. The actual reported number of fatalities during the event and the results from the simulation are shown in Table 1 and Fig. 7. From the survey reports, the community center safely sheltered 43 residents (MuraKami et al. 2012).

Figure 7 shows the evacuation sequence at each shelter in Case A; note that the community center was filled to its capacity-300 people (Table 1) - approximately $25 \mathrm{~min}$ after the earthquake $(\sim 15: 10$ JST). At 15:14 JST, the Japan Meteorological Agency (JMA) issued its first tsunami warning upgrade for the Miyagi coast from $6 \mathrm{~m}$ to over 10 m (JMA 2013), which might explain why some people decided to relocate to a more inland shelter; the community center is only a two-story building (КАнокU Sнгмео 2011), while Yuriage Junior High School is a three-floor building. In addition, information on the damage to the areas in the north where tsunami waves had already struck might also have contributed to their decision. Based on the information provided by survivors, evacuees started moving from the community center to Yuriage Junior High School at approximately 15:30 JST, which agrees with the second tsunami warning information issued by JMA (2013). Therefore, by setting 15:30 JST as the time for the second evacuation in the model, the results showed that a total of 257 evacuees were able to leave the community center before the tsunami arrived. Of the 257 people, only 82 were able to reach 
Table 1

Shelter capacity near Yuriage, the outcome of the 2011 tsunami and the results from Case A and Case B

\begin{tabular}{|c|c|c|c|c|c|}
\hline Shelter & Capacity & 2011 GEJT & Case A & Case B & $\mathrm{B}-\mathrm{A}$ \\
\hline Community center & 300 & $43^{\mathrm{a}}$ & 43 & 300 & +257 \\
\hline Yuriage Junior High School & 2000 & $\sim 1000^{\mathrm{b}}$ & 1050 & 1067 & +17 \\
\hline Yuriage Elementary School & 2300 & $\sim 870^{\mathrm{b}}$ & 699 & 759 & +60 \\
\hline Fatalities & - & $752^{\mathrm{b}}$ & 774 & 436 & -338 \\
\hline
\end{tabular}

The last column shows the reduction in the fatalities when no secondary evacuation behavior was exhibited

a MuraKami et al. (2012)

b Natori city in TAKAGI et al. (2014)

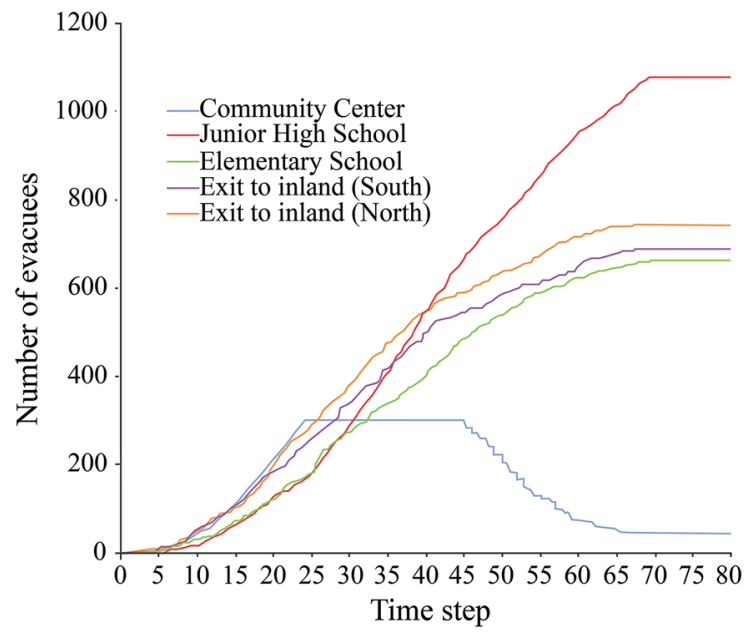

Figure 7

The simulated timeline of the evacuees in the shelters. Note the arrival at the community center (blue line). Approximately $25 \mathrm{~min}$ was necessary to fill the shelter to its full capacity; no additional evacuees arrived or left until $45 \mathrm{~min}$ after the event. Over the next $20 \mathrm{~min}$, people relocated to the junior high school (red line), and the tsunami's arrival resulted in the deaths of evacuees en route

the junior high school in time. The reasons for the fatalities and for the evacuees reaching the high school or not are further explored in the simulations. We summarize some of the reasons as follows. (1) The timing of the secondary evacuation: each evacuee conducted a second evacuation between 15:30 JST and approximately 15:50 JST, when the tsunami arrived at the community center. During this 20-min period, the first people to evacuate might have arrived on time, depending on their means of transportation. (2) The means of transportation: based on the survivor accounts and the simulation results, traffic was congested on the road in front of the community center, and people who attempted to evacuate by car might have been delayed because of this situation. However, in Case B, in which agents did not conduct a secondary evacuation and remained at the community center, the total number of fatalities was approximately $44 \%$ less than in Case A, provided that the community center was filled to its capacity.

This case study shows the advantage of agentbased models. Unlike aggregate and static approaches, modeling low-level component behavior and event scheduling is possible in agent-based models. The immense amount of available data related to the GEJT makes it possible to utilize agent-based approaches to examine an evacuation process defined by more than the sum of its parts instead of a global picture with several assumptions. In addition, agentbased models are powerful tools that can be applied to verify and analyze the effects of evacuees' decisions on the outcomes of the evacuation process. Future evacuation plans and activities for the reconstruction process and urban planning can be supported by the results from tsunami evacuation agent-based models. For example, in the Natori area, a new urban layout has been proposed in which new structural countermeasures and resident relocations would be considered. With a more efficient population distribution, improved road networks, shelter availability, and shorter distances to high ground, a lower tsunami risk is expected. However, a tsunami warning can still trigger a massive evacuation in this area, and the characteristics of such a potential evacuation need to be investigated to avoid accidents or fatalities. Plans for a layout suitable for tsunami protection and a massive evacuation can be explored using agent-based tsunami evacuation simulations. 


\subsection{Shelter Demand: Case of La Punta, Peru}

La Punta is a peninsula in the western part of Callao Province. The area is entirely surrounded by the Pacific Ocean, except on its northeastern side where it is bordered by downtown Callao. This district is one of the smallest in Peru, with 4370 inhabitants and a total land area of $0.75 \mathrm{~km}^{2}$. Historically, earthquakes and tsunamis have struck the area of La Punta in 1586, 1687 and 1746. More than 250 years of seismic inactivity in this region suggests the seismic gap is large enough to trigger earthquakes with an 8.9 magnitude (PULIDO et al. 2013) (Fig. 8).

Tsunami mitigation and preparedness activities have been conducted in La Punta; however, difficulties in conducting frequent evacuation drills with wide population participation suggested it was prudent to apply tsunami evacuation simulations to evaluate the actual conditions of the shelters and the evacuation timing in the area. According to local authorities, 20 official TEBs exist, with enough space to accommodate the entire population (Fig. 9). The authors used the agent-based tsunami evacuation model (MAs et al. 2013a) to investigate a tsunami inundation and the resident evacuation behavior.

A detailed description of the assumptions and constraints for each simulated case can be found in MAs et al. (2013a). In addition to the casualty estimate, more detailed and interesting information is found for the TEBs regarding their capacities and the numbers of evacuees that arrived. At 13 of the 20 evacuation buildings, demand exceeded the available capacity; at the other seven buildings, capacity exceeded the demand, and available space remained. As a consequence, for a total of 4370 residents and buildings with a total capacity for 7930 people, the spatial characteristics of each shelter location produced an imbalance in the preference and number of evacuees during the simulated event. This situation may raise new issues during evacuations, such as

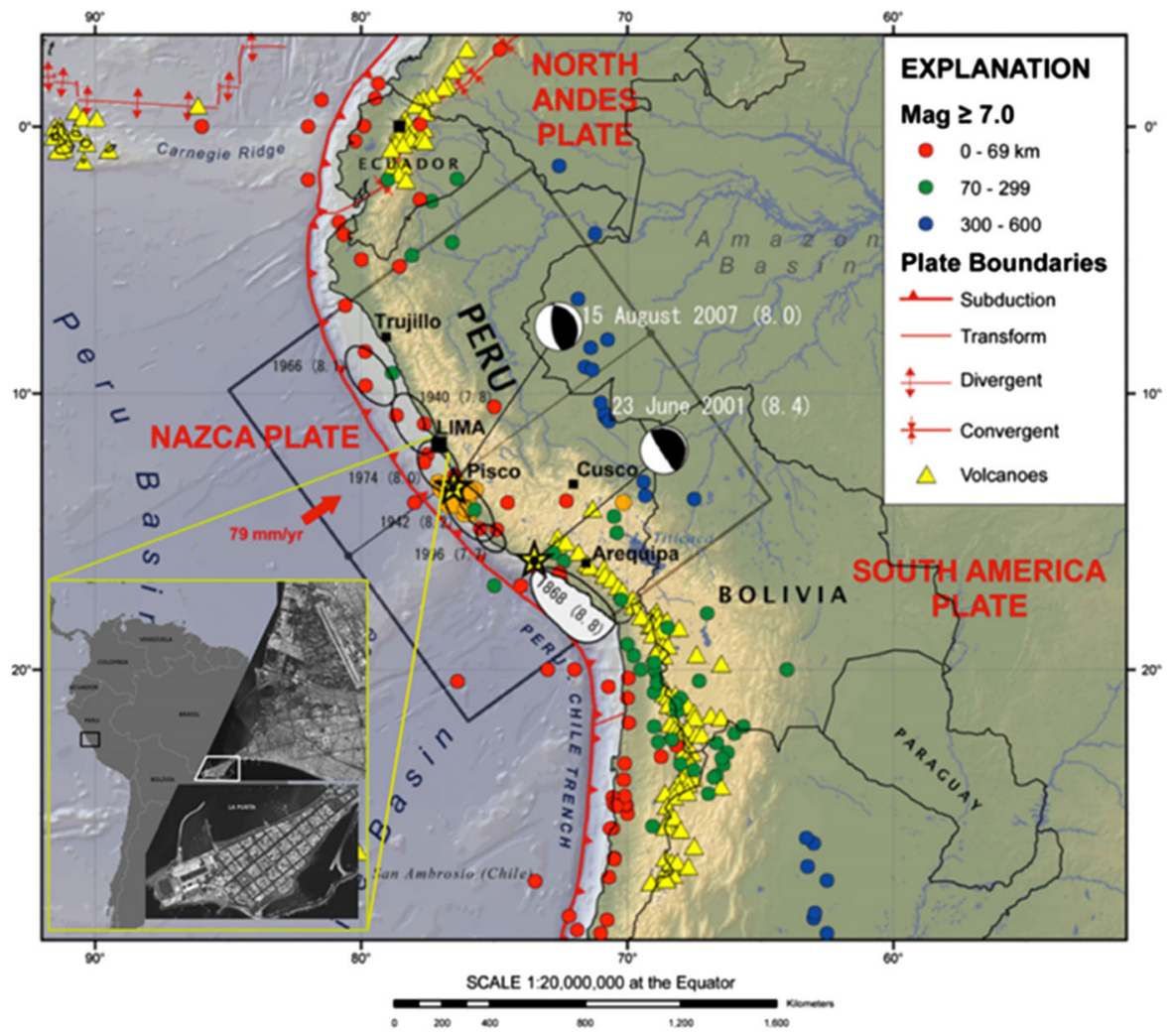

Figure 8

The location of La Punta in Peru and the tectonic settings of the earthquakes in the surrounding regions (modified from YAMAZAKI and ZAVALA 2013; MAS et al. 2013a) 


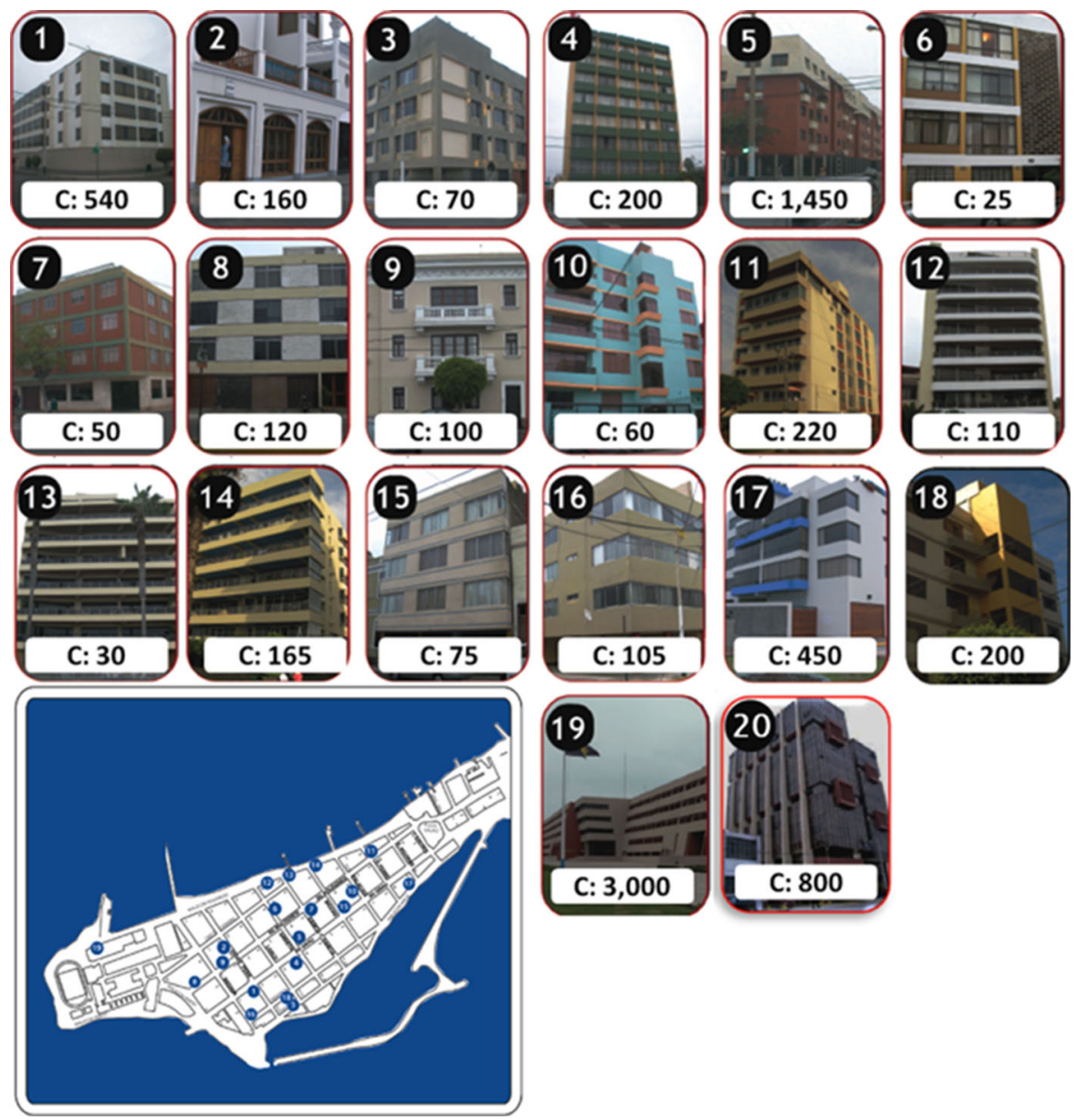

Figure 9

Tsunami evacuation buildings in La Punta. The 20 buildings can accommodate a total of 7930 evacuees in the district of 4370 residents. The bottom-left inset shows the locations of these buildings

conducting a secondary evacuation - as in the case of Natori in Japan discussed previously-that delays evacuation and may cause a higher number of fatalities. To inform the local authorities and stakeholders of these results, the capacity-demand rate of the shelters was mapped. The capacity demand index was constructed to represent and easily communicate the spatial issues of the availability of shelters in La Punta (Fig. 10).

The tsunami evacuation $\mathrm{ABM}$ was used to reveal the necessity of vertically directed evacuations, particularly in low-lying areas such as La Punta. The outcomes of this study contributed to the identification of risks that could not be identified using static approaches (e.g., GIS least-cost distance analysis, shelter location-allocation solutions, or a direct comparison of the available space versus the number of residents without considering the spatiotemporal issues). The dynamics of a tsunami evacuation simulation are valuable characteristics that should be explored and applied in tsunami mitigation and evacuation planning.

\section{Challenges and Future Perspectives}

Each time a tsunami occurs, lessons are gathered and shared; unfortunately, not all lessons are fully learned. Similarly, tsunami evacuation research has substantially improved since the 2004 IOT. The future of tsunami evacuation research, as seen by the authors, concerns the comprehensive geophysics of 

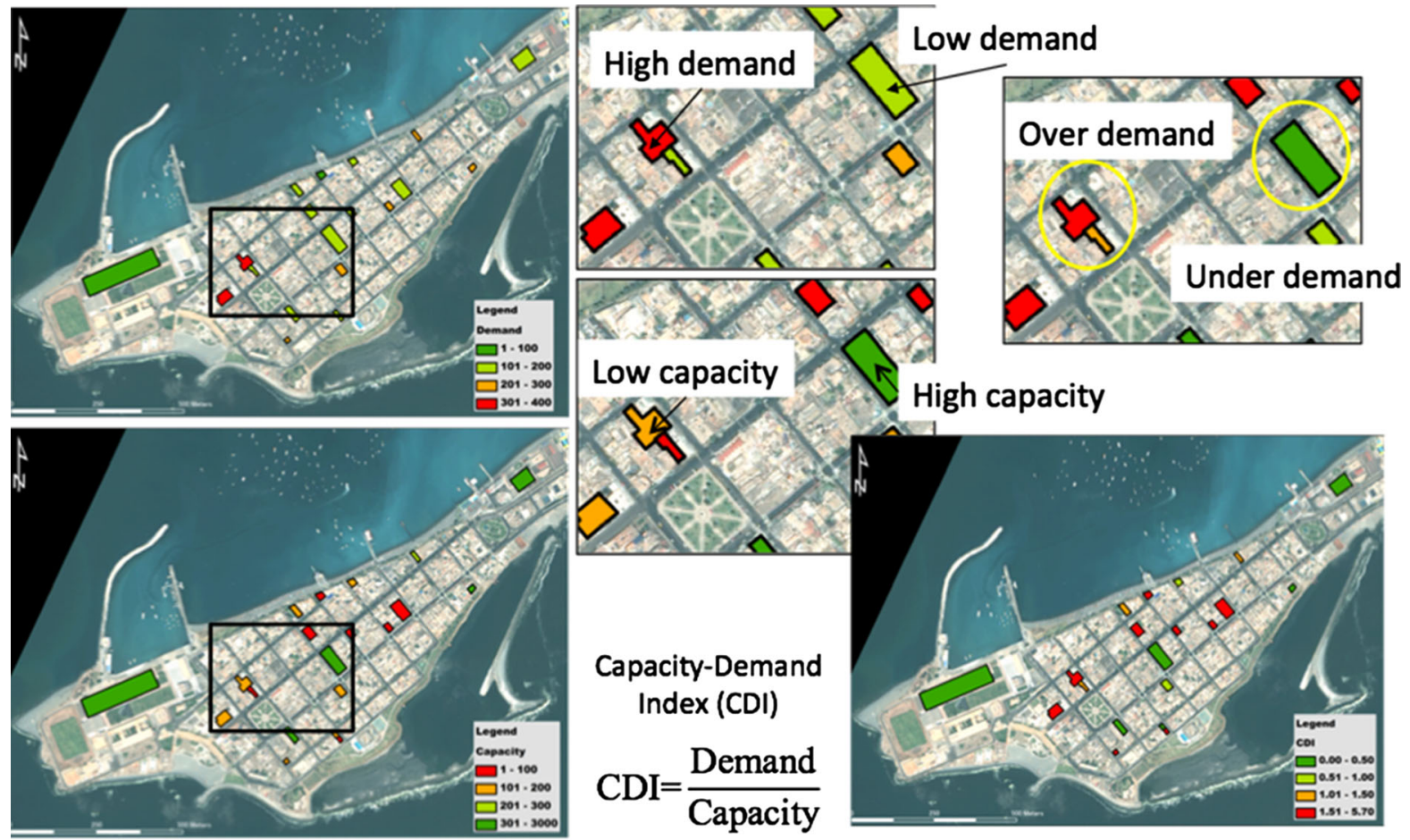

Figure 10

The top-left inset shows the evacuee demand for shelter, while the bottom-left inset shows the capacity of shelters. The black square marks the zoomed-in area with the high/low demand and low/high capacity example of over/under demand evaluations. The bottom-right picture is the CDI mapping result for outreach purposes

tsunamis and the physical and psychological traits of the evacuees, all of which would be built into an integrated modeling technique. Efforts to integrate tsunami simulations and social simulations using agent-based modeling (MAs et al. 2012, 2013a) and to use supercomputers (WiJERATHNe et al. 2013) to bridge gaps between geoscience and social science connect risk assessments with risk management. With these tools, evacuation issues can be understood in a more comprehensive manner. Challenges and emerging issues worth our attention are as follows:

1. Human behavior: Modeling human behavior is not an easy task, but it is not impossible because humans do not behave randomly (KENNEDY 2012). Psychological parameters (VoRST 2010), such as evacuees' cognitive and emotional behaviors that affect decision-making or levels of stress and panic should be included. However, capturing individual characteristics in mathematical equations is difficult (PAN et al. 2007). Human behavior in tsunami evacuations has been studied using questionnaires. Survey responses provide insight into people's risk perceptions (CHARKNOL and TANaboriboon 2006; Bird 2009; Gierlach et al. 2010) and their experiences in real evacuations in post-tsunami events (LACHMAN et al. 1961; Katada et al. 2005; SAito 1990; Mas et al. 2011). The statistical outcomes of preference and revealed surveys are incorporated into the agentbased model presented here to stochastically assess uncertainties in human behavior. In the future, we should explore artificial intelligence and cognitive science models in conjunction with agent-based approaches for tsunami evacuation modeling. Agent-based modeling practitioners use these fields quite often to model human behavior (Wray and Laird 2003; Shendarkar and VAsudevan 2006; Dunin-KePlicz and VerbrugGe 2010).

2. Verification and validation $(\mathrm{V} \& \mathrm{~V})$ of models: Because of the nature of ABMs, which are based 
on simulations rather than equations that can be tested in the laboratory or analytically solved, the process of $\mathrm{V} \& \mathrm{~V}$ is difficult (ORMEROD and Rosewell 2009). However, replication may aid the model verification process. Specifically, if two distinct implementations of a conceptual model are able to produce the same results, then that outcome supports the hypothesis that the original model correctly implemented the conceptual model (RAND and WiLensky 2006). Another way to confirm the "inner validity" of the model is by "alignment", which refers to using a different programming language and $\mathrm{ABM}$ toolkit to reimplement the model (CASTLE and CROOKS 2006). For validation, real-world data must be collected for comparison with model output; this can be done through controlled evacuation drills. Finally, aggregated data on tsunami evacuations or evacuation drills, such as the number of fatalities in an area or the number of evacuees in shelters, are available, but the validity of the dynamics of the evacuees from the starting point to their shelter and the accuracies of the behavioral models used for agents are uncertain.

3. Use of earthquake disaster "big data": To address the challenges in the two items above, human behavioral models and real-world data can be collected from mobile technologies, which record user locations, speeds, directions, etc. This information was tracked during the 2011 GEJT from mobile phones, car navigation systems and social media. This massive amount of data is known as "Shinsai big data" or earthquake disaster big data. These data can elucidate what occurred on the ground on the day of the tsunami, characteristics of evacuee behaviors, and issues in the process of mobilization; in other words, the collective mind of the society at risk can be explored to calibrate behavioral models and to validate evacuation models. Additionally, virtual big data can also be created to gather additional information on human behavior. Here, we introduce the concept of "virtual big data", which is the information gathered via cloud gaming (Liu et al. 2014) to create a library of human behavior in evacuation scenarios. In the future, real-time big data may be used to support the evacuation of residents during an event.

Other expectations in the field of agent-based modeling that apply to tsunami evacuation models of this nature are discussed by Helbing and BaLIETtI (2011), who envision a new way of performing research using supercomputers in data-rich situations. These authors foresee a massive simulation platform with various types of data (i.e., demographic, socioeconomic, and geographic) and simulation approaches (i.e., agent-based and equation-based) in large-scale environments within the next 10-15 years (Helbing and BalietTi 2010).

\section{Conclusions}

The 2004 IOT and the 2011 GEJT were the two most destructive tsunamis in recent years. Both events emphasize the necessity for effective evacuation plans and rapid evacuation behavior. In addition, the events provided large amounts of data that have been or will be used to produce, verify, validate and improve models to represent the evacuation of populations. Tsunami evacuation models have been developed using several techniques; here, we discussed the agent-based modeling approach because we considered it to be suitable for exploring human behavior and rapid low-level environmental changes using available high-resolution data. An agent-based model was applied to assess tsunami risk and evacuation scenarios in Indonesia, Thailand, Peru and Japan. As described in the case studies, agent-based models benefit tsunami mitigation and evacuation planning by describing the individuality of the evacuees and allowing for the observation of emergent behavior within the dynamics of agent interactions. Agent-based models are flexible and provide a natural description of a particular system. From the perspective of tsunami hazard mitigation, the model presented here provides estimates of casualties, an analysis of evacuee behavior in a two-step evacuation process, identifies bottlenecks, uncovers limitations in shelter capacity and evaluates the use of vehicles in evacuations. All of these outcomes are associated with evacuation planning and cannot be 
observed solely through evacuation drills or questionnaire surveys. Finally, several challenges to agent-based modeling exist. Past evacuation simulations for tsunamis were unable to model large-scale scenarios and various human traits; present research is considering much finer levels of detail in simulations with a huge amount of data using highperformance computational techniques. Future research should focus on comprehensive and integrated simulations by incorporating complex agent behavior. Engineering, social, psychological and educational sciences should work together to effectively understand, build, apply and share evacuation simulations and outcomes.

\section{Acknowledgments}

This research was financially supported by Grant-inAid for Scientific Research (Project numbers: 25242035), SATREPS Peru project, CREST project of JST, and IRIDeS grant. In addition, we offer a special thanks to the two anonymous reviewers and the editor in charge of this paper from whom we have received valuable comments that improved the quality of this publication.

Open Access This article is distributed under the terms of the Creative Commons Attribution 4.0 International License (http:// creativecommons.org/licenses/by/4.0/), which permits unrestricted use, distribution, and reproduction in any medium, provided you give appropriate credit to the original author(s) and the source, provide a link to the Creative Commons license, and indicate if changes were made.

\section{REFERENCES}

Abustan, M. S., Harada, E., and Gotoh, H. (2012). Numerical simulation for evacuation process against tsunami disaster at Teluk Batik in Malaysia by multi-agent DEM model. Proceedings of Coastal Engineering, JSCE, 3, 56-60.

Bernard, E., Mofjeld, H. O., Titov, V. V., Synolakis, C. E., and GoNZÁLEZ, F. I. (2006). Tsunami: scientific frontiers, mitigation, forecasting and policy implications. Philosophical Transactions of The Royal Society. Series A, Mathematical, Physical, and Engineering Sciences, 364(1845), 1989-2007. doi:10.1098/rsta. 2006.1809.

BIRD, D.K. (2009). The use of questionnaires for acquiring information on public perception of natural hazards and risk mitigation a review of current knowledge and practice, Natural Hazards and Earth System Sciences, Vol. 9, pp. 1307-1325.
Castle, C. J. E., and Crooks, A. T. (2006). Principles and Concepts of Agent-Based Modelling for Developing Geospatial Simulations (No. 110) (Vol. 44, pp. 1-62).

Charknol, T., and Tanaboriboon, Y. (2006). Tsunami Evacuation Behavior Analysis. IATSS Research, 30(2), 83-96.

Clerveaux, V. I., Katada, T., and Hosol, K. (2008). Tsunami Scenario Simulator: A Tool for ensuring effective disaster management and coastal evacuation in a multilanguage society. Science of Tsunami Hazards, 27(3), 48-71.

Dewi, R. S. (2012). A Gis Based Approach of an Evacuation Model for Tsunami Risk Reduction. Journal of Integrated Disaster Risk Management, 2(2), 1-32. doi:10.5595/idrim.2012.0023.

Dunin-Keplicz, B., and Verbrugge, R. (2010). Teamwork in MultiAgent Systems. A Formal Approach (p. 246). Wiley.

Fraser, S., Leonard, G. S., Matsuo, I., and Murakami, H. (2012). Tsunami evacuation: Lessons from the Great East Japan earthquake and tsunami of March 11th 2011, GNS Science Report (pp. 1-12).

Freire, S., Aubrecht, C., and Wegscheider, S. (2012). When the Tsunami Comes to Town - Improving Evacuation Modeling by Integrating High-resolution Population Exposure. In Proceedings of the 9th International ISCRAM Conference (pp. 1-5). Vancouver, Canada.

Fujoka, M., Ishibashi, K., Kaj, H., and Tsukagoshi, I. (2002). Multi agent Simulation Model for Evaluating Evacuation Management System Against Tsunami Disaster. Journal of Architecture, Planning and Environmental Engineering, 562, 231-236. Retrieved from http://ci.nii.ac.jp/naid/110004660530/.

Gierlach, E., Belsher, B. E., and Beutler, L. E. (2010). Crosscultural differences in risk perceptions of disasters. Risk analysis: an official publication of the Society for Risk Analysis, Vol. 30 , pp. $1539-1549$.

Gonzalez-Riancho, P., Aguirre-Ayerbe, I., Aniel-Quiroga, I., Abad, S., Gonzalez, M., Larreynaga, J., Gavidia, F., Gutierrez, O.Q., Alvarez-Gomez, J.A., and Medina, R. (2013). Tsunami evacuation modelling as a tool for risk reduction: application to the coastal area of El Salvador. Natural Hazards and Earth System Sciences, 13, 3249-3270. doi:10.5194/nhess-13-32492013.

Goto, Y., Affan, M., Agussabti, Nurdin, Y., Yuliana, D. K., and Ardiansyah. (2012). Tsunami Evacuation Simulation for Disaster Education and City Planning. Journal of Disaster Research, 7(1), 92-101. Retrieved from http://www.fujipress.jp/finder/xslt. php? mode $=$ present $\&$ inputfile $=$ DSSTR000700010010.xml.

Helbing, D., Buzna, L., Johansson, A., and Werner, T. (2005). Self-Organized Pedestrian Crowd Dynamics: Experiments, Simulations, and Design Solutions. Transportation Science, 39(1), 1-24. doi:10.1287/trsc.1040.0108.

Helbing, D. and Balietti, S. (2010) From social simulation to integrative system design. Visioneer white paper. http://www. visioneer.ethz.ch.

Helbing, D., and Balietti, S. (2011). How to Do Agent-Based Simulations in the Future: From Modeling Social Mechanisms to Emergent Phenomena and Interactive Systems Design (No. 024) (pp. 1-55).

Hoppe, M., and Marhadiko, H. S. (2009). 30 Minutes in the City of Padang: Lessons for Tsunami Preparedness and Early Warning from the Earthquake on September 30, 2009. Working Document No. 25. GTZ-GITEWS.

Imamura, F., Suzuki, T., and Taniguchi, M. (2001). Development of a Simulation Method for the Evacuation from the Tsunami and 
Its Application to Aonae, Okushiri Is., Hokkaido. Journal of Japan Society for Natural Disaster Science, 20(2), 183-195. Retrieved from http://sciencelinks.jp/j-east/article/200201/00002 0020101A0917476.php.

Imamura, F., Muhari, A., Mas, E., Pradono, M. H., Sugimoto, M., and Post, J. (2012). Tsunami Disaster Mitigation by Integrating Comprehensive Countermeasures in Padang City, Indonesia. Journal of Disaster Research, 7(1). Retrieved from http://www. fujipress.jp/finder/xslt.php?mode=present\&inputfile=DSSTR000 700010006.xml.

Japan Meteorological Agency (JMA). (2013). Lessons learned from the tsunami disaster caused by the 2011 Great East Japan Earthquake and improvements in JMA' s tsunami warning system October 2013 Japan Meteorological Agency (pp. 1-13). Retrieved from: http://www.data.jma.go.jp/svd/eqev/data/en/ tsunami/LessonsLearned_Improvements_brochure.pdf.

Johnston, K. M. (2013). Agent Analyst. Agent-Based Modeling in ArcGIS. (Esri Press, Ed.) (pp. 1-559). California, USA.

KанокU Sнimpo (2011). August 3, 2011 published testimony. Retrieved from: http://ameblo.jp/yume-zuki/entry-10987309620. html.

Katada, T., Asada, J., Kuwasawa, N., and Oikawa, Y. (2000). Development of practical scenario simulator for dissemination of disaster information. Journal of Civil Engineering Information Processing System, 9, 129-136.

Katada, T., Kuwasawa, N., Kanai, M., and Hosoi, K. (2004). Disaster Education for Owase citizen by using Tsunami Scenario Simulator and evaluation of that method. Sociotechnica, 2, 199-208. Retrieved from http://www.jstage.jst.go.jp/article/ sociotechnica/2/0/199/_pdf.

Katada, T., Kodama, M., Kuwasawa, N., and Koshimura, S. (2005). Issues of resident's consciousness and evacuation from the tsunami - From questionnaire survey in Kesennuma city, Miyagi Pref. After the Earthquake of Miyagiken-oki, 2003 Proceedings of the Japan Society of Civil Engineers, 789(2), 93-104. Retrieved from http://www.jstage.jst.go.jp/article/jscej/ 2005/789/789_93/_pdf.

Katada, T., and Kuwasawa, N. (2006). Development of tsunami comprehensive scenario simulator for risk management and disaster education. Transactions of the Japan Society of Civil Engineers (D), 62(3), 250-261.

Kato, S., Shimozono, T., and Okayasu, A. (2009). Hybrid Simulation for Tsunami Evacuation in Consideration of Individual Behaviors. Journal of Japan Society of Civil Engineers, Ser. B2 (Coastal Engineering), 65(1), 1316-1320. doi:10.2208/ kaigan.65.1316.

Kennedy, W.G. (2012) Modelling Human Behavior in AgentBased Models. In Heppenstall, A. J., Crooks, A. T., See, L. M., and Batтy, M. (2012). Agent-Based Models of Geographical Systems (pp. 1-746). Springer.

Kietpawpan, M. (2008). Simulation Approach to Evaluating the Effectiveness of a Tsunami Evacuation Plan for Patong $\mathrm{Mu}-$ nicipality, Phuket, Thailand. Prince of Songkla University.

Lachman, R., Tatsuoka, M., and Bonk, W. J. (1961). Human behavior during the tsunami of May 1960. Science, 133, 1405-1409. Retrieved from http://www.ncbi.nlm.nih.gov/ pubmed/13758063.

Lämmel, G., Rieser, M., Nagel, K., Taubenböck, H., Strunz, G., Goseberg, N., Schlurmann, T., Klüpfel, H., Setiadi, and N. Birkmann, J. (2010). Emergency Preparedness in the case of a Tsunami - Evacuation Analysis and Traffic Optimization for the
Indonesian city of Padang. In W. W. F. KuIngsch, C. Rogsch, A. Schadschneider, and M. Schreckenberg (Eds.), Pedestrian and Evacuation Dynamics 2008 (pp. 171-182). Berlin Heidelberg: Springer. Retrieved from http://www.springerlink.com/index/ R0887H6872071Q07.pdf.

Liu, R., Du, J., and Issa, R.A.R. (2014). Cloud-based deep immersive game for human egress data collection: a framework, Journal of Information Technology in Construction (ITcon), Special Issue BIM Cloud-Based Technology in the AEC Sector: Present Status and Future Trends, Vol. 19, pg. 336-349, http:// www.itcon.org/2014/20.

Mas, E., Imamura, F. and Koshimura, S. (2011). Tsunami Risk Perception Framework for the Start Time Evacuation Modeling, in XXV IUGG General Assembly International Association of Seismology and Physics of Earths Interior, (Melbourne, Australia).

Mas, E., Suppasri, A., Imamura, F., and Koshimura, S. (2012). Agent-based Simulation of the 2011 Great East Japan Earthquake / Tsunami Evacuation: An Integrated Model of Tsunami Inundation and Evacuation. Journal of Natural Disaster Science, 34(1), 41-57. Retrieved from http://www.jsnds.org/contents/ jnds/34_1_3.pdf.

Mas, E., Adriano, B., and Koshimura, S. (2013a). An Integrated Simulation of Tsunami Hazard and Human Evacuation in La Punta, Peru. Journal of Disaster Research, 8(2), 285-295. Retrieved from http://www.fujipress.jp/finder/xslt.php?mode= present\&inputfile=DSSTR000800020008.xml.

Mas, E., Suppasri, A., Srivinok, P., and Koshimura, S. (2013b). Feasibility of Evacuation at the Pakarang Cape in Thailand based on Tsunami Inundation Model and Human Evacuation Simulation. In 10th International Conference on Urban Earthquake Engineering (pp. 1-6). Tokyo, Japan.

Meguro, K., and OdA, K. (2005). Development of Evacuation Simulator for Tsunami Disaster Mitigation. Production Research, 57(4), 343-347.

Munadi, K., Nurdin, Y., Dirhamsyah, M., and Muchalil, S. (2012). Multiagent based Tsunami Evacuation Simulation: A Conceptual Model. In The Proceedings of 2nd Annual International Conference Syiah University 2012 \& 8th IMT Uninet Biosciences Conference (pp. 254-259). Banda Aceh, Indonesia.

Muhari, A., Imamura, F., Koshimura, S., and Post, J. (2011). Examination of three practical run-up models for assessing tsunami impact on highly populated areas. Natural Hazards and Earth System Science, 11(12), 3107-3123. doi:10.5194/nhess-113107-2011.

Muhari, A., Imamura, F., Suppasri, A., Mas, E., and Koshimura, S. (2012). Tsunami arrival time characteristics of 2011 East Japan tsunami revealed from eyewitness, evidences and numerical simulation. Journal of Natural Disaster Science, 34(1), 91-104.

Murakami, H., Такімото, K., and Pomonis, A. (2012). Tsunami Evacuation Process and Human Loss Distribution in the 2011 Great East Japan Earthquake - A Case Study of Natori City, Miyagi Prefecture -. In 15th World Conference on Earthquake Engineering (pp. 1-10). Retrieved from http://www.iitk.ac.in/ nicee/wcee/article/WCEE2012_1587.pdf.

Nguyen, T. N. A., Zucker, J. D., Nguyen, H. Du, Alexis, D., and Vo Duc, A. (2012a). A Hybrid Macro-Micro Pedestrians Evacuation Model to Speed Up Simulation in Road Networks. In AAMAS 2011 Workshop (pp. 371-383).

Nguyen, T. N. A., Zucker, J. D., Nguyen, M. H., Alexis, D., and NGUYEn, H. P. (2012b). Simulation of emergency evacuation of pedestrians along the road networks in Nhatrang city. IEEE, 1-6. 
Nozawa, S., Watanabe, K., and Kondo, A. (2006). Development of Evacuation Simulation Model for Tsunami Disaster. Geographical Information Systems Association, 15, 483-486.

Ormerod, P., and Rosewell, B. (2009). Validation and Verification of Agent-Based Models in the Social Sciences. In F. SQuAzzonI (Ed.), Epistemological Aspects of Computer Simulation in the Social Sciences (pp. 130-140). Berlin: Springer.

Pan, X., Han, C. S., Dauber, K., and Law, K. H. (2007). A multiagent based framework for the simulation of human and social behaviors during emergency evacuations. Ai \& Society, 22(2), 113-132. doi:10.1007/s00146-007-0126-1.

Park, S., van de Lindt, J. W., GuPTA, R., and Cox, D. (2012). Method to determine the locations of tsunami vertical evacuation shelters. Natural Hazards, 891-908. doi:10.1007/s11069-012-0196-3.

Pulido, N., Tavera, H., Aguilar, Z., Nakai, S., and Yamazaki, F. (2013). Strong Motion Simulation of the M8.0 August 15, 200, Pisco Earthquake; Effect of a Multi-Frequency Rupture Process. Journal of Disaster Research, 8(2), 235-242.

RAND, W., and WILENSKY, U. (2006). Verification and Validation through Replication: A Case Study Using Axelrod and Hammond's Ethnocentrism Model. In North American Association for Computational Social and Organization Sciences (NAACSOS) (pp. 1-6). Retrieved from http://ccl.northwestern.edu/ papers/naacsos2006.pdf.

SAITO, T. (1990). Questionnaire Survey of Human Behaviors and Consciousness on the Tsunami of the 1989 Sanriku-Oki Earthquake, Journal of Japan Society for Natural Disaster Science, Vol. 9, No.2, pp. 49-63.

Saito, T., and Kagami, H. (2004). Simulation of Evacuation Behavior from Tsunami utilizing Multi Agent System. In 13th World Conference on Earthquake Engineering (pp. 1-10). Vancouver, B.B., Canada. Retrieved from http://www.iitk.ac.in/ nicee/wcee/article/13_612.pdf.

Shendarkar, A., and VASUdEvan, K. (2006). Crowd Simulation for Emergency Response using BDI Agent Based on Virtual Reality. In L. F. Perrone, F. P. Wieland, J. Liu, B. G. Lawson, D. M. Nicol, and R. M. Fujimoto (Eds.), Proceedings of the 2006 Winter Simulation Conference (pp. 545-553).

Shuto, N. (2009). Tsunami Research - Its Past, Present and near Future -. In Proceedings of the Sixth International Workshop on Coastal Disaster Prevention (pp. 1-24). Bangkok, Thailand.

Simonovic, S. P., and Ahmad, S. (2005). Computer-based Model for Flood Evacuation Emergency Planning. Natural Hazards, 34(1), 25-51. doi:10.1007/s11069-004-0785-X.

Sugimoto, T., Murakami, H., Kozuki, Y., and Nishikawa, K. (2003). A Human Damage Prediction Method for Tsunami Disasters Incorporating Evacuation Activities. Natural Hazards, 2035(29), 585-600.

SuPPASRI, A. (2010). Tsunami Risk Assessment to Coastal Population and building in Thailand. PhD thesis. Tohoku University.

Suppasri, A., Shuto, N., Imamura, F., Koshimura, S., Mas, E., and YALCINER, A. C. (2012a). Lessons Learned from the 2011 Great East Japan Tsunami: Performance of Tsunami Countermeasures, Coastal Buildings, and Tsunami Evacuation in Japan. Pure and Applied Geophysics, 170(6-8), 993-1018. doi:10.1007/s00024-012-0511-7.
Suppasri, A., Koshimura, S., Imai, K., Mas, E., Gokon, H., Muhari, A., and Imamura, F. (2012b). Damage characteristics and field survey of the 2011 Great East Japan Tsunami in Miyagi Prefecture. Coastal Engineering Journal, 54(1), 1250005-1. doi:10. 1142/S0578563412500052.

Suppasri, A., Muhari, A., Ranasinghe, P., Mas, E., Imamura, F., and Koshimura, S. (2014). Damage and Reconstruction After the 2004 Indian Ocean Tsunami and the 2011 Tohoku Tsunami in Tsunami Events and Lessons Learned edited by Kontar, Y., SAnTIAGoFAndino, V., TAKahashi, T. Ed. Springer Netherlands, 2014.

Suzuki, T., and Imamura, F. (2005). Simulation model of the evacuation from a tsunami in consideration of the resident consciousness and behavior. Journal of Japan Society for Natural Disaster Science, 23(4), 521-538. Retrieved from http:// sciencelinks.jp/j-east/article/200509/000020050905A0347269. php.

Synolakis, C. E., and Bernard, E. N. (2006). Tsunami science before and beyond Boxing Day 2004. Philosophical Transactions. Series A, Mathematical, Physical, and Engineering Sciences, 364(1845), 2231-65. doi:10.1098/rsta.2006.1824.

TAKagi, H., Mas, E., and Koshimura, S. (2014). Analysis of the evacuation behavior in Natori, Yuriage during the Great East Japan Earthquake Tsunami. In Annual Meeting of the Tohoku Branch Technology Research Conference, Japan Society of Civil Engineers (Vol. 3, pp. 2011-2012).

Usuzawa, H., Imamura, F., and Shuto, N. (1997). Development of the method for evacuation numerical simulation for tsunami events. In Annual Meeting of the Tohoku Branch Technology Research Conference, Japan Society of Civil Engineers (pp. 430-431). Retrieved from http://library.jsce.or.jp/jsce/open/ 00322/1997/1997-0430.pdf (In Japanese).

Vorst, H. C. M. (2010). Evacuation models and disaster psychology. Procedia Engineering, 3, 15-21. doi:10.1016/j.proeng. 2010.07.004.

Watanabe, K., and Kondo, A. (2009). Development of Tsunami Evacuation Simulation Model to Support Community Planning for Tsunami Disaster Mitigation. Journal of Architecture Planning, 74(637), 627-634.

WatTs, J. M. (1987). Computer Models for Evacuation Analysis. Fire Safety Journal, 12, 237-245.

Wijerathne, M. L. L., Melgar, L. A., Hori, M., Ichimura, T., and TANAKA, S. (2013). HPC Enhanced Large Urban Area Evacuation Simulations with Vision based Autonomously Navigating Multi Agents. Procedia Computer Science, 18, 1515-1524. doi:10.1016/j.procs.2013.05.319.

Wood, N. J., and SchmidtLein, M. C. (2012). Community variations in population exposure to near-field tsunami hazards as a function of pedestrian travel time to safety. Natural Hazards. doi:10. 1007/s11069-012-0434-8.

WRAY, R. E., and LAIRD, J. E. (2003). Variability in Human Behavior Modeling for Military Simulations. In Behavior Representation in Modeling \& Simulation Conference (pp. 1-10).

Yamazaki, F., and Zavala, C. (2013). SATREPS Project on Enhancement of Earthquake and Tsunami Disaster Mitigation Technology in Peru. Journal of Disaster Research, 8(2), 224-234. 